\title{
Metabolic syndrome is associated with and predicted by resting heart rate: a cross-sectional and longitudinal study
}

\author{
Xiongjing Jiang, ${ }^{1}$ Xiaoxue Liu, ${ }^{2}$ Shouling $\mathrm{Wu}_{1}{ }^{3}$ Gus Q Zhang, ${ }^{4}$ Meng Peng, ${ }^{1}$ \\ Yuntao $\mathrm{Wu}^{3}$ Xiaoming Zheng, ${ }^{3}$ Chunyu Ruan, ${ }^{3}$ Weiguo Zhang ${ }^{5}$
}

\begin{abstract}
- Additional material is published online only. To view please visit the journal online (http://dx.doi.org/10.1136/ heartjnl-2014-305685).

${ }^{1}$ Cardiovascular Institute and Fuwai Hospital, Chinese Academy of Medical Sciences and Peking Union Medical College, Beijing, China ${ }^{2}$ Tangshan People's Hospital, Tangshan, Hebei, China ${ }^{3}$ Kailuan General Hospital, Tangshan, Hebei, China ${ }^{4}$ The University of Texas Southwestern Medical Center at Dallas, Dallas, Texas, USA ${ }^{5}$ Cardiovascular and Neurological Institute, Irving, Texas, USA
\end{abstract}

\section{Correspondence to}

Dr Weiguo Zhang,

Cardiovascular and

Neurological Institute,

6771 San Fernando, Irving,

TX 75039, USA;

weiguozha@yahoo.com

$\mathrm{XJ}, \mathrm{XL}$ and SW contributed equally.

Received 10 February 2014 Revised 4 August 2014 Accepted 5 August 2014 Published Online First 1 September 2014

\author{
ABSTRACT \\ Objective Although higher resting heart rate (RHR) has \\ emerged as a predictor for lifespan, the underlying \\ mechanisms remain obscure. The present study \\ investigates whether a positive relationship exists \\ between RHR and metabolic syndrome (MetS) and \\ whether RHR predicts future MetS.
}

Methods A cohort of 89860 participants were surveyed during 2006-2007 in Kailuan/Tangshan, China. MetS was diagnosed when a participant presented at least three of the following: abdominal adiposity, low high density lipoprotein-cholesterol, high triglycerides, hypertension or impaired fasting glucose. RHR was derived from ECG recordings and subjects were stratified based on RHR. Some participants without MetS at baseline were followed-up for 4 years.

Results At baseline, 23150 participants (25.76\%) had MetS. There was a positive association between RHR and MetS. The OR of having MetS was $1.49(95 \% \mathrm{Cl}$ 1.32 to 1.69 ) in subjects with RHR at 95-104 compared with those at 55-64 beats per minute (bpm) (reference), after adjusting for variables including age, sex, education, cigarette smoking, alcohol drinking, physical activities, body mass index, hypertension, diabetes, hyperlipidaemia, inflammatory biomarkers and renal function. More importantly, when 43725 individuals from the original study without MetS at baseline were followed-up, higher RHR was found to predict greater risk of MetS incidence. The OR of developing MetS 4 years later was $1.41(95 \% \mathrm{Cl} 1.21$ to 1.65$)$ in subjects with RHR at 95-104 bpm compared with reference, after all adjustments.

Conclusions Our cross-sectional and longitudinal findings provide evidence that RHR is an independent risk factor for existing MetS and a powerful predictor for future incidence of MetS.

\section{INTRODUCTION}

Resting heart rate (RHR) has recently emerged as a new risk factor that is strongly correlated with lifespan inversely in homoeothermic mammals, especially humans. ${ }^{1-3}$ Several previous investigations have shown that subjects with higher RHR had increased risk of both cardiovascular and all-cause mortality when compared with those with lower RHR in the same cohort. ${ }^{4-7}$ Despite this association, a mechanistic explanation linking higher RHR with increased mortality remains enigmatic.

Metabolic syndrome (MetS) constitutes a cluster of cardiovascular and metabolic risk factors, causing accelerated development of diabetes mellitus, cardiovascular disease, kidney disease and stroke. ${ }^{8}$ According to the National Health and Nutrition Examination Survey 2003-2006, the prevalence of MetS was approximately $34 \%$ in the US adult population. $^{9}$ While the conventional risk factors for developing MetS include overweight/obesity, physical inactivity and family history, identification of other independent risk factors or predictive variables may help in further understanding its pathogenic mechanism and elucidating novel targets for its prevention and treatment.

Given the importance of both higher RHR and MetS in cardiovascular and metabolic abnormalities, in the present study we tested two hypotheses: first, whether a positive relationship exists between RHR and MetS; second, whether RHR is a predictor of future development of MetS. To this end, a large vocational population was surveyed cross-sectionally and followed-up longitudinally for 4 years.

\section{METHODS}

The study was a cohort consisting of the employees of Kailuan Coal Group in Tangshan, China. These coal mine workers (including retirees) received routine health examinations at 11 local hospitals as detailed in previous publications. ${ }^{10} 11$

In the baseline study to determine whether an association exists between RHR and MetS, 101510 participants were screened during 20062007. Exclusion criteria were those without ECG, without laboratory results necessary for a complete MetS evaluation, with RHR $<45$ or $>105$ beats per minute $(\mathrm{bpm})$ and with a history of stroke and myocardial infarction. Of 101510 participants, 89860 were eligible for inclusion. In the 4-year follow-up study to assess whether RHR is a predictor for MetS development, besides the above criteria, subjects with MetS at baseline were excluded. Of 66710 without MetS at baseline, 43725 were eligible for inclusion. No one reported use of nondihydropyridine calcium channel blocker or digitalis in either study.

\section{Data collection}

Data collected included baseline information such as social and demographic factors lifestyle factors and medical history, as previously described. ${ }^{10}{ }^{11}$

Participants were instructed to fast overnight and to refrain from alcohol, cigarette smoking, coffee/ tea and exercise for $\geq 8 \mathrm{~h}$ before taking physical 
examination and laboratory tests. Weight and height (with outdoor clothing and shoes removed) were measured in an upright position from which body mass index (BMI) was calculated. Systolic blood pressure (SBP) and diastolic blood pressure (DBP) were measured twice on each subject at 2 min intervals with the arm cuff kept at the heart level. Readings were made to the nearest $2 \mathrm{~mm} \mathrm{Hg}$ and averaged if the difference was $\leq 5 \mathrm{~mm} \mathrm{Hg}$; otherwise, a third measurement was taken and all three readings were averaged. Venous blood was obtained for determination of routine chemistry, including fasting blood glucose (FBG), high density lipoprotein-cholesterol (HDL), total cholesterol and triglycerides (TG). RHR was measured and calculated from ECG recordings after subjects acclimating hospital setting $\geq 30 \mathrm{~min}$ and in supine position $\geq 5 \mathrm{~min}$.

\section{MetS diagnosis}

MetS was diagnosed when a subject fulfilled three or more of the following components: waist circumference $\geq 90 \mathrm{~cm}$ for men or $\geq 80$ for women; TG $\geq 1.7 \mathrm{mmol} / \mathrm{L} ; \mathrm{HDL}<1.03 \mathrm{mmol} /$ $\mathrm{L}$ for men or $<1.30 \mathrm{mmol} / \mathrm{L}$ for women; SBP/DBP $\geq 130 /$ $85 \mathrm{~mm} \mathrm{Hg}$ or current use of antihypertensive medications; FBG $\geq 5.6 \mathrm{mmol} / \mathrm{L}$ or previously diagnosed type 2 diabetes or current use of hypoglycaemic agents or insulin. ${ }^{8}$

\section{Statistics}

Study participants were stratified by RHR. A logistic regression model was used to evaluate the ORs and 95\% CIs of having MetS for each RHR stratification with a reference, with adjustment for potential confounders. Tests of linear trend across incremental RHR values were performed by assigning the median value to each RHR category and treating it as a continuous variable. A multiple linear regression model was used to assess the association of RHR with BMI, hypertension, diabetes and hyperlipidaemia. A likelihood ratio test was used to eliminate the potential modifying effect of sex and obesity status (defined as BMI $>24 \mathrm{~kg} / \mathrm{m}^{2}$ ). When appropriate, natural $\log$ -

Table 1 Characteristics of the subjects according to baseline resting heart rate (RHR) in a cross-sectional study in 2006

\begin{tabular}{|c|c|c|c|c|c|c|c|}
\hline RHR stratification, bpm & $45-54$ & $55-64$ & $65-74$ & $75-84$ & $85-94$ & 95-104 & $\mathrm{p}$ Value \\
\hline No of subjects & 1269 & 13073 & 37381 & 28043 & 7457 & 2637 & \\
\hline Mean RHR, bpm & $51.69 \pm 2.17$ & $60.86 \pm 2.45$ & $69.84 \pm 2.27$ & $78.60 \pm 1.83$ & $88.92 \pm 2.64$ & $98.93 \pm 2.73$ & $<0.0001$ \\
\hline Males (\%) & $1082(85.26)$ & $10545(80.66)$ & $29316(78.42)$ & $22553(80.42)$ & $6095(81.74)$ & $2214(83.96)$ & $<0.0001$ \\
\hline Age, years & $55.08 \pm 12.91$ & $52.49 \pm 12.40$ & $50.90 \pm 12.17$ & $50.36 \pm 12.29$ & $50.70 \pm 12.96$ & $52.53 \pm 13.41$ & $<0.0001$ \\
\hline \multicolumn{8}{|l|}{ Education } \\
\hline Illiteracy (\%) & $25(2.06)$ & $144(1.15)$ & $348(0.96)$ & $252(0.92)$ & $96(1.32)$ & $33(1.28)$ & $<0.0001$ \\
\hline Primary school (\%) & $150(12.39)$ & $1171(9.33)$ & $3110(8.59)$ & $2299(8.35)$ & $629(8.62)$ & $263(10.24)$ & \\
\hline Middle school (\%) & $931(76.88)$ & 10178 (81.09) & 30188 (83.34) & $23124(84.03)$ & 6061 (83.04) & $2126(82.76)$ & \\
\hline College/university (\%) & $105(8.67)$ & $1058(8.43)$ & $2578(7.12)$ & $1843(6.70)$ & $513(7.03)$ & $147(5.72)$ & \\
\hline \multicolumn{8}{|l|}{ Smoking } \\
\hline Never (\%) & $699(56.33)$ & $7536(59.53)$ & $21979(60.41)$ & $16374(59.23)$ & $4309(58.56)$ & $1584(61.16)$ & $<0.0001$ \\
\hline Former (\%) & $93(7.49)$ & $781(6.17)$ & $1903(5.23)$ & $1346(4.87)$ & $387(5.26)$ & $151(5.83)$ & \\
\hline Current (\%) & 449 (36.18) & $4342(34.30)$ & 12499 (34.36) & $9924(35.90)$ & $2662(36.18)$ & $855(33.01)$ & \\
\hline \multicolumn{8}{|l|}{ Alcohol drinking } \\
\hline Never (\%) & $658(53.02)$ & $7078(55.88)$ & 21461 (58.97) & $16291(58.92)$ & 4299 (58.42) & $1587(61.27)$ & $<0.0001$ \\
\hline Former $(\%)$ & $60(4.83)$ & 439 (3.47) & $1271(3.49)$ & $876(3.17)$ & 277 (3.76) & $92(3.55)$ & \\
\hline Current (\%) & $523(42.14)$ & $5150(40.66)$ & $13662(37.54)$ & $10482(37.91)$ & $2783(37.82)$ & $911(35.17)$ & \\
\hline \multicolumn{8}{|l|}{ Physical activities } \\
\hline Inactive (\%) & $83(6.85)$ & $981(7.84)$ & 2995 (8.29) & $2740(9.97)$ & $758(10.40)$ & $239(9.32)$ & $<0.0001$ \\
\hline Moderately active (\%) & $876(72.34)$ & $9535(76.18)$ & $27156(75.18)$ & $20789(75.66)$ & $5694(78.11)$ & $2040(79.53)$ & \\
\hline Very active (\%) & $252(20.81)$ & 2001 (15.99) & $5968(16.52)$ & 3947 (14.37) & $838(11.50)$ & $286(11.15)$ & \\
\hline Hypertension (\%) & $410(32.31)$ & $4520(34.58)$ & $15250(40.80)$ & $12800(45.64)$ & $3792(50.85)$ & $1528(57.94)$ & $<0.0001$ \\
\hline Dyslipidaemia (\%) & $332(26.16)$ & $3896(29.80)$ & 12479 (33.38) & $10200(36.37)$ & 2903 (38.93) & $1031(39.10)$ & $<0.0001$ \\
\hline Diabetes mellitus (\%) & $56(4.41)$ & $753(5.76)$ & $2889(7.73)$ & $2788(9.94)$ & $1015(13.61)$ & 448 (16.99) & $<0.0001$ \\
\hline $\mathrm{BMI}, \mathrm{kg} / \mathrm{m}^{2}$ & $24.35 \pm 3.29$ & $24.74 \pm 3.36$ & $25.09 \pm 3.44$ & $25.13 \pm 3.52$ & $25.08 \pm 3.67$ & $24.77 \pm 3.83$ & $<0.0001$ \\
\hline SBP, mm Hg & $125.50 \pm 20.53$ & $126.59 \pm 20.03$ & $129.26 \pm 20.27$ & $131.99 \pm 20.73$ & $135.37 \pm 22.22$ & $138.10 \pm 22.84$ & $<0.0001$ \\
\hline $\mathrm{DBP}, \mathrm{mm} \mathrm{Hg}$ & $78.28 \pm 10.08$ & $80.48 \pm 10.78$ & $82.68 \pm 11.23$ & $84.55 \pm 12.07$ & $85.95 \pm 12.54$ & $87.33 \pm 12.99$ & $<0.0001$ \\
\hline $\mathrm{TG}, \mathrm{mmol} / \mathrm{L}$ & $1.38 \pm 1.03$ & $1.52 \pm 1.16$ & $1.65 \pm 1.33$ & $1.73 \pm 1.47$ & $1.86 \pm 1.58$ & $1.89 \pm 1.53$ & $<0.0001$ \\
\hline $\mathrm{HDL}, \mathrm{mmol} / \mathrm{L}$ & $1.58 \pm 0.39$ & $1.57 \pm 0.40$ & $1.56 \pm 0.40$ & $1.53 \pm 0.40$ & $1.57 \pm 0.42$ & $1.63 \pm 0.45$ & $<0.0001$ \\
\hline $\mathrm{LDL}, \mathrm{mmol} / \mathrm{L}$ & $2.13 \pm 0.82$ & $2.21 \pm 0.88$ & $2.34 \pm 0.94$ & $2.41 \pm 0.90$ & $2.36 \pm 0.88$ & $2.34 \pm 0.90$ & $<0.0001$ \\
\hline $\mathrm{TC}, \mathrm{mmol} / \mathrm{L}$ & $4.75 \pm 1.17$ & $4.86 \pm 1.12$ & $4.91 \pm 1.15$ & $5.01 \pm 1.12$ & $5.06 \pm 1.20$ & $5.08 \pm 1.19$ & $<0.0001$ \\
\hline $\mathrm{FBG}, \mathrm{mmol} / \mathrm{L}$ & $5.02 \pm 1.23$ & $5.20 \pm 1.28$ & $5.35 \pm 1.50$ & $5.58 \pm 1.71$ & $5.84 \pm 2.08$ & $6.16 \pm 2.50$ & $<0.0001$ \\
\hline $\mathrm{CRP}^{*}, \mathrm{mg} / \mathrm{L}$ & $0.65(0.24-1.80)$ & $0.71(0.29-2.04)$ & $0.80(0.30-2.26)$ & $0.80(0.30-2.01)$ & $0.97(0.36-2.51)$ & $1.03(0.38-2.96)$ & $<0.0001$ \\
\hline $\mathrm{UA}, \mathrm{mmol} / \mathrm{L}$ & $299.19 \pm 82.84$ & $290.75 \pm 82.24$ & $287.04 \pm 82.18$ & $287.61 \pm 83.09$ & $293.68 \pm 87.14$ & $290.92 \pm 87.82$ & $<0.0001$ \\
\hline $\mathrm{CR}, \mu \mathrm{mol} / \mathrm{L}$ & $91.25 \pm 32.07$ & $90.25 \pm 26.95$ & $92.88 \pm 30.44$ & $90.74 \pm 30.41$ & $90.84 \pm 33.20$ & $89.76 \pm 31.66$ & $<0.0001$ \\
\hline WC, $\mathrm{cm}$ & $86.16 \pm 9.41$ & $86.68 \pm 10.11$ & $86.76 \pm 9.94$ & $87.32 \pm 10.05$ & $87.54 \pm 10.50$ & $86.93 \pm 10.54$ & $<0.0001$ \\
\hline$\beta$-Blocker use (\%) & $4(0.32)$ & $43(0.33)$ & $102(0.27)$ & $86(0.31)$ & $25(0.34)$ & $11(0.42)$ & 0.7255 \\
\hline
\end{tabular}

${ }^{*}$ CRP was not normally distributed and values presented are median (IQR).

$\mathrm{BMI}$, body mass index; CR, creatine; CRP, C reactive protein; DBP, diastolic blood pressure; FBG, fasting blood glucose; HDL, high density lipoprotein-cholesterol; LDL, low density lipoprotein-cholesterol; SBP, systolic blood pressure; TC, total cholesterol; TG, triglycerides; UA, uric acid; WC, waist circumference. 


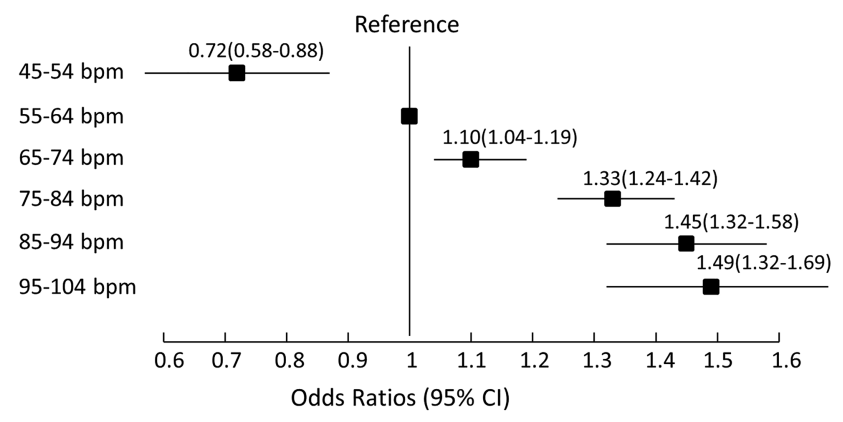

Figure 1 Stratified resting heart rate and OR $(95 \% \mathrm{Cl})$ of having metabolic syndrome in an association study after adjustments (model 1: age and sex; model 2: education, smoking, alcohol drinking and physical activities; model 3: body mass index, hypertension, diabetes and hyperlipidaemia; model 4: C reactive protein; model 5: further adjusted for creatine).

transformed values were used. All data were analysed with statistical software SPSS V.13.0 (SPSS Inc, Chicago). A probability (p) value $<0.05$ was considered statistically significant. All $\mathrm{p}$ values are two-sided. Data are reported as mean \pm SD for general characteristics or mean \pm SEM for regression analysis.

\section{RESULTS}

\section{Cross-sectional investigation}

The general characteristics of the population are shown in table 1. RHR was stratified at incremental intervals of 45-54, 55-64, 65-74, 75-84, 85-94 and 95-104 bpm. Clinical exam and laboratory results showed that most of the cardiovascular and metabolic risks including MetS components, such as hypertension, obesity, hyperlipidaemia and impaired glucose metabolism, tended to accompany the increase of RHR.

At baseline, 23150 out of 89860 subjects (25.76\%) had MetS. When RHR range of 55-64 bpm was set as reference (see online supplementary table S1), the OR of having MetS increased progressively across the lowest to highest RHR stratification with the ORs of 0.72 (95\% CI 0.58 to 0.88 ), 1 (reference), 1.36 (1.29 to 1.43 ), 1.76 (1.67 to 1.85$), 2.12$ (1.99 to $2.27)$ and $2.30(2.10$ to 2.52$)$ respectively $\left(p_{\text {trend }}<0.0001\right)$ after adjustment for age and sex (Model 1). After further adjustment for education, smoking, alcohol drinking and physical activities
(Model 2), for BMI, hypertension, diabetes and hyperlipidaemia (Model 3), for inflammatory markers (Model 4) and renal function (Model 5), the ORs remained statistically significant ( $p_{\text {trend- }}$ $<0.0001)$. With all adjustments, the OR of having MetS was 1.49 (95\% CI 1.32 to 1.69 ) in subjects with RHR at 95-104 compared with the reference of 55-64 bpm (figure 1).

Table 2 shows regression analyses of RHR against other study parameters. In both simple and multiple adjusted linear regression analyses, RHR was positively associated with FBG, TG and DBP after controlling for age and sex (Model 1). After adding additional controls in stepwise from Models 2 to 5, the positive associations remained statistically significant $(\mathrm{p}<0.0001)$. There was a negative association between RHR and HDL, after controlling for BMI, hypertension, diabetes and hyperlipidaemia, for inflammatory markers and for renal function $(p<0.0001)$. Supplement file shows mean and 95\% CI.

\section{Longitudinal investigation}

RHR was stratified as same as in the baseline study. Of 43725 subjects without MetS in 2006-2007, 11593 (26.51\%) developed MetS at 4 years (table 3). When RHR of 55-64 bpm was set as reference (see online supplementary table S2), the risk of developing MetS increased progressively across the lowest to highest RHR ranges with the ORs of 0.77 (0.64 to 0.93 ), 1 (reference), 1.12 (1.06 to 1.19$), 1.25$ (1.17 to 1.33 ), 1.31 (1.19 to $1.43)$ and $1.42(1.23$ to 1.62$)$ respectively $\left(p_{\text {trend }}<0.0001\right)$ after adjustment for Model 1. After further adjustments from Models 2 to 5 in stepwise, the ORs remained almost unchanged, and statistically significant $\left(\mathrm{p}_{\text {trend }}<0.0001\right)$. With all adjustments, OR of having MetS 4 years later was 1.41 (95\% CI 1.21 to $1.65)$ in subjects with RHR at 95-104 compared with the reference of 55-64 bpm (figure 2).

Table 4 shows regression analyses of RHR against other study parameters at the end of the follow-up. In both simple and multiple adjusted linear regression analyses, RHR was positively associated with FBG, TG and DBP after controlling for age and sex. Additional stepwise adjustments from Models 2 to 5 did not materially change the positive associations $(p<0.0001)$. Supplement file shows mean and 95\% CI.

\section{DISCUSSION}

RHR is intricately regulated by important and complex interactions of multiple mechanisms, including sympathetic and

Table 2 Adjusted regression coefficient of resting heart rate with cardiovascular and metabolic related parameters in a cross-sectional study in 2006

\begin{tabular}{|c|c|c|c|c|c|c|c|c|c|c|}
\hline & $\begin{array}{l}\text { Model } 1 \\
\text { B (SEM) }\end{array}$ & p Value & $\begin{array}{l}\text { Model } 2 \\
\text { B (SEM) }\end{array}$ & p Value & $\begin{array}{l}\text { Model } 3 \\
\text { B (SEM) }\end{array}$ & p Value & $\begin{array}{l}\text { Model } 4 \\
\text { B (SEM) }\end{array}$ & p Value & $\begin{array}{l}\text { Model } 5 \\
\text { B (SEM) }\end{array}$ & p Value \\
\hline FBG & $0.8148(0.0190)$ & $<0.0001$ & $0.8178(0.0193)$ & $<0.0001$ & $0.7677(0.0279)$ & $<0.0001$ & $0.7668(0.0279)$ & $<0.0001$ & $0.7580(0.0279)$ & $<0.0001$ \\
\hline TG & $0.4958(0.0227)$ & $<0.0001$ & $0.4871(0.0230)$ & $<0.0001$ & $0.3421(0.0279)$ & $<0.0001$ & $0.3437(0.0279)$ & $<0.0001$ & $0.3811(0.0281)$ & $<0.0001$ \\
\hline $\mathrm{HDL}$ & $0.1035(0.0787)$ & 0.1882 & $0.0566(0.0810)$ & 0.4848 & $-0.2909(0.0849)$ & 0.0006 & $-0.2813(0.0851)$ & 0.0009 & $-0.2201(0.085)$ & 0.0098 \\
\hline WC & $0.0307(0.0033)$ & $<0.0001$ & $0.0321(0.0033)$ & $<0.0001$ & $0.0208(0.0042)$ & $<0.0001$ & $0.0183(0.0043)$ & $<0.0001$ & $0.0159(0.0043)$ & 0.0002 \\
\hline BMI & $0.0696(0.0090)$ & $<0.0001$ & $0.0710(0.0091)$ & $<0.0001$ & $-0.0619(0.0096)$ & $<0.0001$ & $-0.0684(0.0096)$ & $<0.0001$ & $-0.0637(0.0096)$ & $<0.0001$ \\
\hline SBP & $0.0778(0.0016)$ & $<0.0001$ & $0.0783(0.0016)$ & $<0.0001$ & $0.0685(0.0021)$ & $<0.0001$ & $0.0683(0.0021)$ & $<0.0001$ & $0.0697(0.0021)$ & $<0.0001$ \\
\hline DBP & $0.1364(0.0027)$ & $<0.0001$ & $0.1360(0.0028)$ & $<0.0001$ & $0.1231(0.0035)$ & $<0.0001$ & $0.1234(0.0035)$ & $<0.0001$ & $0.1252(0.0035)$ & $<0.0001$ \\
\hline CRP & $0.0527(0.0050)$ & $<0.0001$ & $0.0584(0.0051)$ & $<0.0001$ & $0.0572(0.0051)$ & $<0.0001$ & $0.0572(0.0051)$ & $<0.0001$ & $0.0562(0.0051)$ & $<0.0001$ \\
\hline UA & $-0.0001(0.0004)$ & 0.7791 & $0.0005(0.0004)$ & 0.2534 & $-0.0012(0.0004)$ & 0.0047 & $-0.0013(0.0004)$ & 0.0026 & $-0.0008(0.0004)$ & 0.0570 \\
\hline CR & $-0.0061(0.0011)$ & $<0.0001$ & $-0.0069(0.0011)$ & $<0.0001$ & $-0.0139(0.0011)$ & $<0.0001$ & $-0.0138(0.0011)$ & $<0.0001$ & $-0.0138(0.0011)$ & $<0.0001$ \\
\hline
\end{tabular}

See Results section for adjustment models.

BMI, body mass index; CR, creatine; CRP, C reactive protein; DBP, diastolic blood pressure; FBG, fasting blood glucose; HDL, high density lipoprotein-cholesterol; SBP, systolic blood pressure; TG, triglycerides; UA, uric acid; WC, waist circumference. 
Table 3 Characteristics of the subjects (initially without metabolic syndrome) after 4-year follow-up according to resting heart rate (RHR)

\begin{tabular}{|c|c|c|c|c|c|c|c|}
\hline RHR stratification, bpm & $45-54$ & $55-64$ & $65-74$ & $75-84$ & $85-94$ & 95-104 & $\mathrm{p}$ Value \\
\hline No. of subjects (2010) & 787 & 7868 & 16133 & 12913 & 3147 & 1145 & \\
\hline No. of subjects (2006) & 704 & 7051 & 19076 & 12763 & 3096 & 1035 & \\
\hline Mean RHR (2010), bpm & $51.75 \pm 2.29$ & $60.91 \pm 2.46$ & $69.90 \pm 2.49$ & $78.47 \pm 2.91$ & $89.02 \pm 2.60$ & $98.6397 \pm 2.69$ & $<0.0001$ \\
\hline Mean RHR (2006), bpm & $51.73 \pm 2.15$ & $60.86 \pm 2.46$ & $69.79 \pm 2.27$ & $78.47 \pm 2.85$ & $88.93 \pm 2.58$ & $98.97 \pm 2.73$ & $<0.0001$ \\
\hline Males (\%) & $590(83.81)$ & $5597(79.38)$ & $14635(76.72)$ & $9959(78.03)$ & $2467(79.68)$ & $868(83.86)$ & $<0.0001$ \\
\hline Age, years & $52.36 \pm 12.38$ & $49.78 \pm 12.01$ & $48.18 \pm 11.73$ & $47.06 \pm 11.65$ & $46.44 \pm 12.07$ & $47.48 \pm 13.10$ & $<0.0001$ \\
\hline \multicolumn{8}{|l|}{ Education } \\
\hline Illiteracy (\%) & $9(1.34)$ & $41(0.61)$ & $107(0.58)$ & $65(0.52)$ & $14(0.46)$ & $8(0.79)$ & $<0.0001$ \\
\hline Primary school (\%) & $71(10.55)$ & $475(7.02)$ & $1094(5.92)$ & $699(5.58)$ & $169(5.57)$ & 70 (6.94) & \\
\hline Middle school (\%) & $520(77.27)$ & $5612(82.97)$ & $15827(85.69)$ & $10839(86.50)$ & $2595(85.50)$ & $863(85.53)$ & \\
\hline College/university (\%) & $73(10.85)$ & $636(9.40)$ & $1443(7.81)$ & $928(7.41)$ & $257(8.47)$ & 68 (6.74) & \\
\hline \multicolumn{8}{|l|}{ Smoking } \\
\hline Never (\%) & $392(57.23)$ & $4147(60.87)$ & 11501 (62.07) & $7582(60.28)$ & $1795(58.85)$ & $593(58.42)$ & $<0.0001$ \\
\hline Former (\%) & $52(7.59)$ & $362(5.31)$ & $849(4.58)$ & $515(4.09)$ & $136(4.46)$ & $57(5.62)$ & \\
\hline Current (\%) & $241(35.18)$ & $2304(33.82)$ & $6180(33.35)$ & $4481(35.63)$ & $1119(36.69)$ & $365(35.96)$ & \\
\hline \multicolumn{8}{|l|}{ Alcohol drinking } \\
\hline Never (\%) & 359 (52.49) & $3785(55.51)$ & $11084(59.80)$ & $7483(59.48)$ & $1762(57.81)$ & $604(59.51)$ & $<0.0001$ \\
\hline Former $(\%)$ & $25(3.65)$ & $186(2.73)$ & $514(2.77)$ & $317(2.52)$ & 79 (2.59) & $32(3.15)$ & \\
\hline Current (\%) & $300(43.86)$ & $2847(41.76)$ & $6936(37.42)$ & $4780(38.00)$ & $1207(39.60)$ & 379 (37.34) & \\
\hline \multicolumn{8}{|l|}{ Physical activities } \\
\hline Inactive (\%) & $42(6.24)$ & $571(8.47)$ & $1594(8.66)$ & $1240(9.91)$ & $316(10.43)$ & $108(10.71)$ & $<0.0001$ \\
\hline Moderately active (\%) & $494(73.40)$ & $5177(76.75)$ & $14317(77.76)$ & $9873(78.93)$ & $2430(80.17)$ & 786 (77.98) & \\
\hline Very active (\%) & $137(20.36)$ & $997(14.78)$ & $2501(13.58)$ & $1395(11.15)$ & $285(9.40)$ & $114(11.31)$ & \\
\hline Hypertension (\%) & $171(24.29)$ & $1743(24.72)$ & $5622(29.47)$ & 4179 (32.74) & $1122(36.24)$ & $450(43.48)$ & $<0.0001$ \\
\hline Dyslipidaemia (\%) & 140 (19.89) & $1520(21.56)$ & $4461(23.39)$ & $3214(25.18)$ & $778(25.13)$ & $275(26.57)$ & $<0.0001$ \\
\hline Diabetes mellitus (\%) & $14(1.99)$ & $196(2.78)$ & $575(3.01)$ & $502(3.93)$ & $160(5.17)$ & $74(7.15)$ & $<0.0001$ \\
\hline $\mathrm{BMI}, \mathrm{kg} / \mathrm{m}^{2}$ & $24.12 \pm 3.23$ & $24.22 \pm 3.15$ & $24.46 \pm 3.19$ & $24.39 \pm 3.23$ & $24.29 \pm 3.32$ & $23.92 \pm 3.41$ & $<0.0001$ \\
\hline $\mathrm{SBP}, \mathrm{mm} \mathrm{Hg}$ & $122.06 \pm 19.75$ & $122.21 \pm 18.18$ & $124.25 \pm 18.33$ & $126.21 \pm 18.78$ & $128.36 \pm 19.84$ & $131.53 \pm 20.67$ & $<0.0001$ \\
\hline $\mathrm{DBP}, \mathrm{mm} \mathrm{Hg}$ & $77.44 \pm 9.74$ & $78.73 \pm 10.17$ & $80.50 \pm 10.45$ & $81.89 \pm 11.27$ & $82.85 \pm 11.50$ & $84.31 \pm 11.78$ & $<0.0001$ \\
\hline $\mathrm{TG}, \mathrm{mmol} / \mathrm{L}$ & $1.23 \pm 0.88$ & $1.28 \pm 0.91$ & $1.37 \pm 1.01$ & $1.40 \pm 1.11$ & $1.44 \pm 1.08$ & $1.51 \pm 1.13$ & $<0.0001$ \\
\hline $\mathrm{HDL}, \mathrm{mmol} / \mathrm{L}$ & $1.61 \pm 0.38$ & $1.59 \pm 0.38$ & $1.59 \pm 0.39$ & $1.56 \pm 0.37$ & $1.59 \pm 0.38$ & $1.64 \pm 0.40$ & $<0.0001$ \\
\hline $\mathrm{LDL}, \mathrm{mmol} / \mathrm{L}$ & $2.08 \pm 0.85$ & $2.19 \pm 0.86$ & $2.29 \pm 0.90$ & $2.34 \pm 0.85$ & $2.32 \pm 0.84$ & $2.32 \pm 0.91$ & $<0.0001$ \\
\hline $\mathrm{TC}, \mathrm{mmol} / \mathrm{L}$ & $4.69 \pm 1.14$ & $4.82 \pm 1.02$ & $4.84 \pm 1.09$ & $4.92 \pm 1.05$ & $4.96 \pm 1.07$ & $4.96 \pm 1.13$ & $<0.0001$ \\
\hline $\mathrm{FBG}, \mathrm{mmol} / \mathrm{L}$ & $4.93 \pm 1.07$ & $5.01 \pm 0.99$ & $5.05 \pm 1.04$ & $5.20 \pm 1.21$ & $5.34 \pm 1.38$ & $5.51 \pm 1.84$ & $<0.0001$ \\
\hline CRP, mg/L & $0.57(0.20-1.70)$ & $0.62(0.23-1.90)$ & $0.69(0.24-1.94)$ & $0.62(0.22-1.69)$ & $0.72(0.28-1.94)$ & $0.81(0.28-2.20)$ & $<0.0001$ \\
\hline $\mathrm{UA}, \mathrm{mmol} / \mathrm{L}$ & $290.35 \pm 80.16$ & $281.56 \pm 79.25$ & $276.66 \pm 77.10$ & $275.50 \pm 78.35$ & $277.23 \pm 80.17$ & $277.34 \pm 78.65$ & $<0.0001$ \\
\hline $\mathrm{CR}, \mu \mathrm{mol} / \mathrm{L}$ & $88.93 \pm 21.63$ & $89.52 \pm 25.62$ & $92.04 \pm 27.19$ & $89.14 \pm 25.76$ & $89.06 \pm 30.71$ & $90.22 \pm 31.97$ & $<0.0001$ \\
\hline WC, $\mathrm{cm}$ & $84.71 \pm 9.23$ & $84.63 \pm 9.62$ & $84.44 \pm 9.28$ & $84.30 \pm 9.31$ & $84.14 \pm 9.95$ & $83.33 \pm 9.56$ & $<0.0001$ \\
\hline Stroke (\%) & $15(2.13)$ & $123(1.74)$ & $239(1.25)$ & $182(1.43)$ & $41(1.32)$ & $16(1.55)$ & 0.0344 \\
\hline Myocardial infarction (\%) & $8(1.14)$ & $65(0.92)$ & $145(0.76)$ & $124(0.97)$ & $25(0.81)$ & $11(1.06)$ & 0.3469 \\
\hline All-cause mortality (\%) & $1(0.14)$ & $16(0.23)$ & $29(0.15)$ & $15(0.12)$ & $3(0.10)$ & $2(0.19)$ & 0.4969 \\
\hline$\beta$-Blocker use (\%) & $1(0.14)$ & $11(0.16)$ & $25(0.13)$ & $9(0.07)$ & $3(0.10)$ & $3(0.29)$ & 0.2804 \\
\hline
\end{tabular}

See table 1 for CRP value explanation.

BMI, body mass index; CR, creatine; CRP, C reactive protein; DBP, diastolic blood pressure; FBG, fasting blood glucose; HDL, high density lipoprotein-cholesterol; LDL, low density lipoprotein-cholesterol; SBP, systolic blood pressure; TC, total cholesterol; TG, triglycerides; UA, uric acid; WC, waist circumference.

parasympathetic nervous system, hormonal system, lifestyle factors and environment. Long recognised as one of the 'vital signs' of clinical medicine, heart rate is frequently obtained but generally unused outside of acute clinical setting. Studies in thermostatic mammals have suggested a correlation between RHR and lifespan. ${ }^{12}$ Recent human studies have increasingly shown an epidemiological association between higher RHR and all-cause mortality in general population, but a mechanistic explanation remains obscure. ${ }^{4-7} 12$ Speculatively, increased oxidative stress or reactive oxygen species, pro-inflammation cytokines, decreased arterial wall compliance and distensibility, and telomere shortening have all been proposed as mechanisms to link higher RHR to shortened longevity. ${ }^{2} 13$ The present study add to the existing body of knowledge in elucidating the pathophysiological role of increased RHR in mortality. Our finding that RHR is associated with existing MetS is consistent with previous studies showing that blood pressure and serum glucose were already adversely influenced by higher RHR, ${ }^{14} 15$ as well as a handful of smaller scale, cross-sectional studies showing that MetS was associated with higher RHR. ${ }^{16-18}$ More importantly, however, the present result shows that RHR is also a powerful predictor for future incidence of MetS. An increased incidence of MetS serves well as a link between increased RHR and increased cardiovascular and all-cause mortality, because the clinical risks of MetS are well recognised. In a recent systematic review and meta-analysis of 87 studies (951083 patients), 


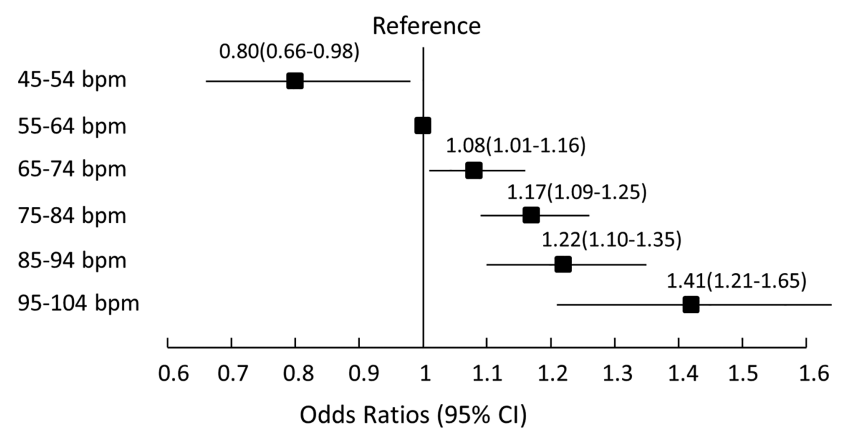

Figure 2 Stratified resting heart rate and OR $(95 \% \mathrm{Cl})$ of developing metabolic syndrome (MetS) in 4 years in those without MetS in a longitudinal follow-up study (see figure 1 for adjustment details).

individuals with MetS had $>2$-fold increased risk of cardiovascular disease, cardiovascular mortality and stroke compared with those without. ${ }^{19}$ Additionally, in those with MetS the relative risk of developing type 2 diabetes was $>5$-fold higher, ${ }^{20}$ and the mortality risk from coronary disease was $>3$-fold higher. ${ }^{21}$ Taken together, it becomes clear that MetS plays a role, at least in part, in the translation of higher RHR into increased mortality risk. This raises new and intriguing implications about the importance of RHR in clinical evaluation and prognostic calculations.

MetS is conventionally managed by both pharmacological and non-pharmacological (ie, lifestyle) approaches, targeting specific core disorders such as obesity, hypertension and hyperlipidaemia. In current clinical practice, however, with the exception of emergency and critical care and situations of symptomatic tachycardia, bradycardia or specific arrhythmias, RHR alone is generally not an intervention target. Unless the patient becomes symptomatic, it is largely neglected that, for example when treating hypertension, direct vasodilators may increase RHR through baroreceptor reflexes, $\beta$-blockers and non-dihydropyridine calcium channel antagonists may decrease RHR by blocking $\beta$-adrenergic mediated cyclic adenosine monophosphate (cAMP) production or by blocking the inward current of calcium during myocardial pacemaker cells depolarisation. ${ }^{2} 22$ In terms of non-pharmacological therapies, lifestyle modifications are irreplaceable for general health and wellbeing, for example, aerobatic exercise effectively lowers RHR by augmenting parasympathetic tone and improving endothelial function, with better blood pressure, body weight and blood lipid profile. ${ }^{23}$ Supplementation of $\omega-3$ fatty acids (ie, eicosapentaenoic acid or EPA and docosahexaenoic acid or DHA)) slows RHR as well. ${ }^{24} 25$

Since each component of MetS, including obesity, hyperlipidaemia, hypertension and glucose intolerance, is established as an independent risk factor for cardiovascular morbidity and mortality, appropriate clinical practice seeks comprehensive management of all modifiable risk factors. In the present study, after all adjustments for other variables, RHR emerges as an independent risk factor for MetS and a predictor of MetS incidence. Given these facts, it is now reasonable to ask whether RHR alone should become a new target of clinical intervention, just as other risk factors like hyperlipidaemia and hypertension. In this regard, several pressing areas of future research are looked for: whether different responses in RHR occurring as sideeffects from existing MetS clinical interventions result in different clinical outcomes; and whether deliberate targeting of RHR as a clinical intervention results in different outcomes in clinic patients or even in healthy, asymptomatic individuals. Funny channel inhibitors may help in such a testing because its bradycardic effect accompanies less haemodynamic and hormonal alterations; ${ }^{26}$ and whether revision of clinical definition of tachycardia needs is needed. As has been the case with blood pressure and lipid profiles, advances in medical knowledge have led to continued and frequent revisions of what constitutes a 'healthy' or 'goal' value. In light of the increasing significance of heart rate, the 2013 European Society of Hypertension/ European Society of Cardiology guidelines for the management of arterial hypertension have already emphasised that blood pressure measurement should always be with the measurement of heart rate. ${ }^{27}$ Given the predictive power of RHR for cardiovascular and metabolic burden, as well as the fact that RHR measurement is convenient, fast and virtually cost-free (eg, pulse rate by palpation), the increasing importance of RHR in evaluating the impact of interventional therapy and in medical decision-making cannot be understated.

There are some strengths in the present study: To our knowledge, this is the first large scale investigation in the field. The sample size in the present study allowed us to make adjustments for a number of potential confounding variables. The 4-year follow-up of participants without MetS at baseline is also the first to investigate RHR as a predictor of MetS incidence, rather than merely an associated variable. In our study, RHR was

Table 4 Adjusted regression coefficient of resting heart rate with cardiovascular and metabolic related parameters after 4-year follow-up

\begin{tabular}{|c|c|c|c|c|c|c|c|c|c|c|}
\hline & $\begin{array}{l}\text { Model } 1 \\
\text { B (SEM) }\end{array}$ & $p$ Value & $\begin{array}{l}\text { Model } 2 \\
\text { B (SEM) }\end{array}$ & $p$ Value & $\begin{array}{l}\text { Model } 3 \\
\text { B (SEM) }\end{array}$ & $p$ Value & $\begin{array}{l}\text { Model } 4 \\
\text { B (SEM) }\end{array}$ & $\mathrm{p}$ Value & $\begin{array}{l}\text { Model } 5 \\
\text { B (SEM) }\end{array}$ & $p$ Value \\
\hline FBG & $0.8387(0.0383)$ & 0.0001 & $0.8450(0.0388)$ & $<0.0001$ & $0.9539(0.0510)$ & $<0.0001$ & $0.9574(0.0511)$ & $<0.0001$ & $0.9368(0.0511)$ & $<0.0001$ \\
\hline TG & $0.3844(0.0428)$ & $<0.0001$ & $0.3571(0.0432)$ & $<0.0001$ & $0.3784(0.0502)$ & $<0.0001$ & $0.3794(0.0504)$ & $<0.0001$ & $0.4306(0.0506)$ & $<0.0001$ \\
\hline HDL & $0.3678(0.11662)$ & 0.0016 & $0.4177(0.1203)$ & 0.0005 & $-0.1208(0.1262)$ & 0.3385 & $-0.1187(0.1265)$ & 3480 & $-0.0145(0.1269)$ & 0.9092 \\
\hline WC & $-0.0105(0.0049)$ & 0.0313 & $-0.0082(0.0050)$ & 0.0989 & $0.0028(0.0060)$ & 0.6351 & $0.0009(0.0060)$ & 0.8753 & $-0.0016(0.0060)$ & 0.7905 \\
\hline BMI & $-0.0079(0.0137)$ & 0.5629 & $-0.0023(0.0139)$ & 0.8685 & $-0.070(0.0142)$ & $<0.0001$ & $-0.0750(0.0142)$ & $<0.0001$ & $-0.0663(0.0143)$ & $<0.0001$ \\
\hline SBP & $0.0748(0.0025)$ & $<0.0001$ & $0.0764(0.0025)$ & $<0.0001$ & $0.0725(0.0032)$ & $<0.0001$ & $0.0721(0.0032)$ & $<0.0001$ & $0.0739(0.0032)$ & $<0.0001$ \\
\hline DBP & $0.1269(0.0041)$ & $<0.0001$ & $0.1282(0.0042)$ & $<0.0001$ & $0.1219(0.0053)$ & $<0.0001$ & $0.1219(0.0053)$ & $<0.0001$ & $0.1246(0.0053)$ & $<0.0001$ \\
\hline CRP & $0.0333(0.0071)$ & $<0.0001$ & $0.0367(0.0073)$ & $<0.0001$ & $0.0415(0.0073)$ & $<0.0001$ & $0.0415(0.0073)$ & $<0.0001$ & $0.0400(0.0073)$ & $<0.0001$ \\
\hline UA & $-0.0033(0.0006)$ & $<0.0001$ & $-0.0030(0.0006)$ & $<0.0001$ & $-0.0037(0.0006)$ & $<0.0001$ & $-0.0038(0.0006)$ & $<0.0001$ & $-0.0034(0.0006)$ & $<0.0001$ \\
\hline CR & $-0.0096(0.0017)$ & $<0.0001$ & $-0.0109(0.0017)$ & $<0.0001$ & $-0.0177(0.0018)$ & $<0.0001$ & $-0.0176(0.0018)$ & $<0.0001$ & $-0.0176(0.0018)$ & $<0.0001$ \\
\hline
\end{tabular}

See Results section for adjustment models.

BMI, body mass index; CR, creatine; CRP, C reactive protein; DBP, diastolic blood pressure; FBG, fasting blood glucose; HDL, high density lipoprotein-cholesterol; SBP, systolic blood pressure; TG, triglycerides; UA, uric acid; WC, waist circumference. 
derived from ECG, enabling a precise RHR measurement. The limitation of the study includes is that despite large sample size, the cohort is vocational and with an unbalanced sex ratio, which may limit the extrapolation of the results to more general population. Future randomised controlled studies are needed as already noted in the Discussion section. Also, while statistical analyses can adjust for known confounding variables, only randomisation can account for potentially unknown or unmeasured confounding variables.

\section{CONCLUSIONS}

The present study provides evidence that higher RHR is an independent risk factor for existing MetS and for impending incidence of MetS in those without MetS at baseline. The relationship between RHR and MetS materialises a mechanism by which RHR increases the risk of cardiovascular and all-cause mortality. From a clinical perspective, RHR becomes an increasingly important element in making therapeutic decisions and evaluating the outcomes, and may emerge as an additional and independent interventional target even in healthy, asymptomatic individuals. The present study raises intriguing questions about the conventional definition of 'normal/physiological' range of RHR. From a research perspective, future studies are needed to investigate the effects of deliberately targeting RHR on MetS and other outcomes. From a public health perspective, RHR measurement constitutes a simple and inexpensive approach to monitor general cardiovascular and metabolic health in population.

\section{Key messages}

\section{What is already known on this subject?}

- Resting heart rate (RHR) has emerged as a new risk factor that inversely correlates with lifespan in humans.

- The mechanisms by which higher RHR increases cardiovascular and all-cause mortality remain obscure.

\section{What might this study add?}

- There is a strong and positive association between RHR and metabolic syndrome (MetS) in a large cohort cross-sectionally.

- Moreover, in those without MetS, higher RHR predicts higher incidence of MetS longitudinally.

- The relationship between RHR and MetS is likely one of the mechanisms by which RHR increases the risk of cardiovascular and all-cause mortality.

\section{How might this impact on clinical practice?}

- From a cardiovascular and metabolic perspective, the significance of RHR in making therapeutic decisions and evaluating the outcomes cannot be overlooked.

- From a public health perspective, RHR measurement constitutes a simple and inexpensive approach in monitoring cardiovascular and metabolic health (or risks) in the population.

Acknowledgements We thank all participants and research staff for their invaluable contributions.

Contributors All listed authors: concept and design and/or analysis and interpretation of data. XJ, SW, GQZ, MP and WZ: drafting of the manuscript or revising it critically for important intellectual content. WZ: final approval of the manuscript submitted.
Funding This work was supported by Kailuan Coal Mine Group.

Competing interests WZ was an employee of DSM when the manuscript was accepted.

\section{Patient consent Obtained.}

Ethics approval Obtained from the local Institutional Ethics Committee.

Provenance and peer review Not commissioned; externally peer reviewed.

Data sharing statement The raw data of this article are available on request.

\section{REFERENCES}

1 Levine HJ. Rest heart rate and life expectancy. J Am Coll Cardiol 1997;30:1104-6.

2 Zhang GQ, Zhang W. Heart rate, lifespan, and mortality risk. Ageing Res Rev 2009:8:52-60.

3 Palatini P. Elevated heart rate: a "new" cardiovascular risk factor? Pro Cardiovasc Dis 2009;52:1-5.

4 Jouven $\mathrm{X}$, Empana JP, Schwartz PJ, et al. Heart-rate profile during exercise as a predictor of sudden death. New Engl J Med 2005;352:1951-8.

5 Tverdal A, Hjellvik V, Selmer R. Heart rate and mortality from cardiovascular causes: a 12 year follow-up study of 379,843 men and women aged 40-45 years. Eur Heart J 2008;29:2772-81

6 Mao Q, Huang JF, Lu X, et al. Heart rate influence on incidence of cardiovascular disease among adults in China. Int J Epidemiol 2010;39:1638-46.

7 Plichart M, Thomas F, Empana JP, et al. Gender-specific trends in heart rate in the general population from 1992-2007: a study of 226,288 French adults. Eur J Prev Cardiol 2013;20:61-72.

8 Grundy SM, Cleeman Jl, Daniels SR, et al. Diagnosis and management of the metabolic syndrome: an American Heart Association/National Heart, Lung, and Blood Institute Scientific Statement. Circulation 2005;112:2735-52.

9 Ervin RB. Prevalence of metabolic syndrome among adults 20 years of age and over, by sex, age, race and ethnicity, and body mass index: United States 20032006. Natl Health Stat Report 2009:5:1-7.

10 Wang A, Liu X, Guo X, et al. Resting heart rate and risk of hypertension: results of the Kailuan cohort study. J Hypertens 2014;32:1600-5.

11 Peng $M$, Wu $S$, Jiang $X$, et al. Long-term alcohol consumption is an independent risk factor of hypertension development in northern china: Evidence from kailuan study. J Hypertens 2013;31:2342-7.

12 Jouven $X$, Empana JP, Escolano $S$, et al. Relation of heart rate at rest and long-term ( $>20$ years) death rate in initially healthy middle-aged men. Am J Cardiol 2009;103:279-83.

13 Palatini P. Heart rate as an independent risk factor for cardiovascular disease: Current evidence and basic mechanisms. Drugs 2007;67(Suppl 2):3-13.

14 Koopman RJ, Mainous AG III, Everett CJ, et al. Tool to assess likelihood of fasting glucose impairment (tag-it). Ann Fam Med 2008;6:555-61.

15 Inoue $T$, Iseki $K$, Iseki $C$, et al. Higher heart rate predicts the risk of developing hypertension in a normotensive screened cohort. Circ J 2007;71:1755-60.

16 O'Hartaigh B, Jiang CQ, Bosch JA, et al. Influence of heart rate at rest for predicting the metabolic syndrome in older chinese adults. Acta Diabetol 2013;50:325-31.

17 Rogowski O, Steinvil A, Berliner S, et al. Elevated resting heart rate is associated with the metabolic syndrome. Cardiovasc Diabetol 2009;8:55

18 Oda E, Aizawa Y. Resting heart rate predicts metabolic syndrome in apparently healthy non-obese japanese men. Acta Diabetol 2014;51:85-90.

19 Mottillo S, Filion KB, Genest J, et al. The metabolic syndrome and cardiovascular risk a systematic review and meta-analysis. J Am Coll Cardiol 2010;56:1113-32.

20 Lorenzo C, Okoloise M, Williams K, et al. The metabolic syndrome as predictor of type 2 diabetes: the Aan Antonio Heart Study. Diabetes Care 2003;26:3153-9.

21 Lakka HM, Laaksonen DE, Lakka TA, et al. The metabolic syndrome and total and cardiovascular disease mortality in middle-aged men. JAMA 2002;288:2709-16.

22 Zhang W. Can we use calcium antagonist better in antihypertensive therapy? Circadian consideration. Pharmacological Res 1996;34:187-91.

23 Carter JB, Banister EW, Blaber AP. Effect of endurance exercise on autonomic control of heart rate. Sports Med 2003;33:33-46.

24 Cicero AF, Derosa G, Di Gregori V, et al. Omega 3 polyunsaturated fatty acids supplementation and blood pressure levels in hypertriglyceridemic patients with untreated normal-high blood pressure and with or without metabolic syndrome: A retrospective study. Clin Exp Hypertens 2010;32:137-44.

25 Mozaffarian D, Geelen A, Brouwer IA, et al. Effect of fish oil on heart rate in humans: a meta-analysis of randomized controlled trials. Circulation 2005; 112:1945-52.

26 Difrancesco D. The role of the funny current in pacemaker activity. Cir Res 2010;106:434-46.

27 Mancia G, Fagard R, Narkiewicz K, et al.; Task Force Members. 2013 ESH/ESC Guidelines for the management of arterial hypertension: The Task Force for the management of arterial hypertension of the European Society of Hypertension (ESH) and of the European Society of Cardiology (ESC). J Hypertens 2013;31:1281-357. 